\title{
LINGUAGEM E SIGNO NO DE MAGISTRO DE SANTO AGOSTINHO
}

\author{
LANGUAGE AND SIGN IN THE DE MAGISTRO OF SANTO AGOSTINHO
}

Alexssandro Vidal da Silva*

\section{RESUMO}

O De Magistro de Santo Agostinho, colóquio em que seu filho, Adeodato, é o interlocutor, pondera acerca da linguagem enquanto sons significativos, sua finalidade, força interior e a palavra em suas dimensões. O presente trabalho de pesquisa analisa os temas da linguagem e a relação signo e realidade, na referida obra. Partindo do pressuposto de que a linguagem é um instrumento constitutivo dos processos comunicativos do ser humano, esta pesquisa aborda em primeiro lugar a linguagem enquanto sons significativos, a fim de responder ao problema do que vem a ser a fala e no que ela se constitui. É apresentada, em segundo lugar, uma reflexão sobre os signos e seus significados, o que eles significam e como o fazem, abrindo espaço para a reflexão sobre a relação entre os signos e a realidade e, ainda, a sua eficácia e seus limites, uma vez que os sinais são elementos fundamentais no processo da linguagem humana.

PALAVRAS-CHAVE: linguagem; signo; significado; comunicação; Agostinho.

\section{ABSTRACT}

The De Magistro of Santo Agostinho, colloquium whose son, Adeodato, is the interlocutor, ponders about language as meaningful sounds, it's purpose, inner strength and the word in it's dimensions. The present research work analyzes the themes of language and the relationship between sign and reality, in the referred work. Based on the assumption that language is a constitutive instrument of human communicative processes, this research firstly addresses language as meaningful sounds, in order to answer the problem of what speech is and what it constitutes. Secondly, it's presented a reflection on signs and their meanings, what they mean and how they do it is presented, opening space for reflection on the relationship between signs and reality and, still, their effectiveness and their limits, since signs are fundamental elements in the human language process.

KEYWORDS: language; sign; meaning; communication; Agostinho.

\section{INTRODUÇÃO}

Este trabalho teve como objetivo investigar como a linguagem se expressa por meio de signos a partir da obra De Magistro ${ }^{1}$ de Santo Agostinho. Assim, perpassamos pela análise da linguagem enquanto sons significativos e pela relação signo e realidade. As principais ideias presentes nesta pesquisa são: o conceito de linguagem enquanto sons significativos, a natureza do signo, a relação do signo e a realidade, reciprocidade dos signos e sua arbitrariedade.

\footnotetext{
* Graduado em Filosofia pela PUC Minas. E-mail: alexssandrovidal@ @otmail.com.

${ }^{1}$ A obra De Magistro será, a partir deste momento, citada como DM.
} 
O processo relacional humano é marcadamente linguístico e racional. Quando a linguagem busca descortinar sua origem, instrumentos e finalidade, ela se torna um objeto/tema do discurso filosófico. Conhecer o processo de comunicação humana é fundamental para o estabelecimento de relações e vida social.

A importância deste estudo reside no fato de que a linguagem é o meio usado para expressar o conteúdo de nosso intelecto, ou, como diz Agostinho, exteriorizar o sinal da vontade por meio da articulação do som. Usada pelo ser humano em seu processo de comunicação, ela se vale de instrumentos eficientes para que seu fim seja atingido com êxito. Os sinais são instrumentos a serviço da linguagem e é na sua relação com a realidade que o significado é descortinado àquele que se comunica. Em tal processo, a fala ganha destaque.

A reflexão agostiniana no $D M$ avança sobre o tema da linguagem na vanguarda dessa discussão no século IV e $\mathrm{V}$ e, mesmo assim, o autor dessa obra é um grande influente das discussões na atualidade no que diz respeito à linguagem.

Santo Agostinho converteu-se ao cristianismo em 386, após seu contato com Santo Ambrósio de Milão. Uma vez batizado, sua mudança de comportamento gradual o conduz, primeiramente, à ordem do presbiterato em 391 e, posteriormente, ao episcopado. A nova fé lhe era objeto de estudo, para a qual buscou fundamento filosófico.

\section{LINGUAGEM: SONS SIGNIFICATIVOS}

Agostinho se valeu da filosofia grega como instrumento capaz de dar sistematização racional e conferir autoridade ao cristianismo. Sua filosofia busca conciliar as verdades da fé com aquelas racionais do pensamento helênico, revestindo a revelação cristã de elementos da especulação filosófica (PESSANHA, 1984, p. 12). O conjunto do Corpus Agostinianus precisa ser compreendido dentro de seu período de vida, uma vez que a sua conversão trouxe implicações diretas ao seu modo de pensar. Assim, as obras antes e depois de sua conversão possuem características próprias e díspares quanto aos elementos que ele agrega vindos do cristianismo.

É no período após a sua conversão que Agostinho escreve o $D M$, obra em que trata da problemática da linguagem intimamente ligada à teoria do conhecimento ${ }^{2}$. Embora não seja o

\footnotetext{
${ }^{2}$ O $D M$ é um dos textos filosóficos mais proeminentes de Agostinho. Escrita em 389, a referida obra contém os fundamentos da teoria do conhecimento desenvolvida por ele e se estrutura em forma de um diálogo, em que ele demonstra a dependência entre palavra e pensamento. Essa obra tem como interlocutores o próprio autor,
} 
pioneiro nesta temática ${ }^{3}$ " “Agostinho foi de fato considerado, no âmbito da Patrística, o primeiro a formular uma teoria linguística original, ainda que com os limites devidos ao contexto histórico às finalidades de sua visão prático-teórica” (SANTOS, 1997, p. 151).

A função da linguagem pode ser compreendida como ensinar e recordar. Para que as palavras recordadas sejam ensinadas, o locutor faz uso da fala. É mediante a fala que as palavras saem da memória e tornam-se sinais àquele que as ouve. Agostinho $(D M, \mathrm{I}, 2)$ define o fenômeno falar da seguinte maneira: "quem fala, pois, dá exteriormente o sinal da sua vontade por meio da articulação do som”. A fala é, nesse sentido, um instrumento a serviço da vontade daquele que quer emitir uma informação. Ela não possui em si mesma a mensagem a ser transmitida; é, contudo, o sinal que a expressa. A partir disso, podem-se mensurar alguns elementos fundamentais da fala ${ }^{4}$ : primeiro, a exteriorização de uma vontade interna, sendo esta manifestada por meio da fala; segundo, a utilização de sinais, dentre eles a própria fala; e, por fim, a realidade de sons articulados, a formulação de palavras e frases por meio de fonemas. $\mathrm{O}$ propósito de quem fala é o de externar aos outros os conteúdos da própria mente ${ }^{5}$. Esta aspiração, manifestada por meio da emissão de palavras, evidencia anseios: seja transmitir conhecimento ou absorver ideias também internas de outros indivíduos.

A finalidade da linguagem é a de ensinar e suscitar recordações (aprender) por meio dos sentidos e pensamentos (SANTOS, 1997, p. 153-154). Logo, o indivíduo que exercita o canto sozinho, somado ao uso de palavras, que é uma atividade mental, está provocando a memória na busca da coisa mesma, trazendo-a à mente em um processo de recordação. O conteúdo já está dado na memória, ele só é trazido à mente por meio de seus sinais. Assim acontece também no diálogo entre dois interlocutores: quando o emissor diz uma palavra ao receptor, este busca a palavra em sua memória, depois, esta envia à mente a própria coisa que a palavra representa, acontecendo assim o processo de recordação no diálogo.

A linguagem racional, propriamente humana, com a finalidade de ensinar e recordar, pode ser resumidamente apresentada no $D M$ como "um instrumento prático através da qual

\footnotetext{
Agostinho, e seu filho, Adeodato. No $D M$ os principais objetos de discussão são: a relação entre linguagem, signo e significante, o recordar e a interioridade (SANTOS, 1997, p. 151-152).

${ }^{3}$ Segundo Maia (2017, p. 73), outros autores já refletiram de modo sistemático sobre a questão da linguagem. "O problema do alcance da linguagem não se inicia exatamente com Santo Agostinho, mas já é problematizado antes, como podemos constatá-lo em Plotino ao tratar do princípio (arché) de todas as coisas, isto é, o Uno, que está acima de toda predicação, sendo chamado de 'além do Ser' ou 'Sobre-Ser'."

${ }^{4}$ Ver em Santos (1997, p. 168, nota 8).

${ }^{5} \mathrm{O}$ termo não é aqui usado no sentido hodierno do seu conceito, especialmente daquelas questões concernentes à filosofia da mente, mas contextualizado no período patrístico de Agostinho. Portanto, não devedor dessas questões da filosofia contemporânea.
} 
estamos em condição de ensinar e de dar informações, de evocar à memória fatos ou conceitos e recordá-los aos outros: ela expressa a vontade de quem fala" (SANTOS, 1997, p. 153). Para ser eficiente ela se vale basicamente de signos.

[...] pode-se resumir sua definição dos signos, em De Magistro, da seguinte maneira: é um instrumento arbitrário ${ }^{6}$ criado pela razão para expressar as realidades do mundo externo e interno; portanto, está em relação de substituição para com outra coisa. Ao ser utilizado na comunicação, seu significado adere à memória e, por isso, pode servir como instrumento de aprendizagem, na medida em que incita ao conhecimento das coisas. (KIRCHOF, 2011, p. 117, grifos do autor).

Principal elemento num processo comunicativo, o significado dos signos está presente na memória dos interlocutores. O ensino se dá por meio de signos. A recordação são palavras ou signos pronunciados. Antes de o objeto ser evocado da memória, é um signo que o sinaliza. É visitando o palácio da memória que se chega a estes sinais (AGOSTINHO, Confissões, X, 8, 14).

No que concerne aos sinais escritos, é importante frisar que há uma diversidade de sinais que aguçam a mente pelos sentidos: visuais, físicos, sonoros etc., ou seja, signos que vão além das palavras escritas ou pronunciadas. Os surdos se comunicam por meio de gestos, por exemplo. Sem palavras, coisas visíveis, sons e sabores também podem ser mostrados (AGOSTINHO DM, III, 5).

Dentro da diversidade de signos, tem-se signos visuais e signos auditivos. As palavras ditas entram na categoria destes; enquanto que as escritas, daqueles. Sinteticamente, as palavras “[...] não são os únicos signos, pois os gestos são signos visuais tal como as palavras são signos auditivos" (GILSON, 2006, p. 140).

O ensino gira em torno da linguagem. Por meio dos signos, aquele que ensina dá àquele que aprende o sinal referente ao objeto a ser conhecido. Mas é importante frisar uma vez mais que a palavra não é a coisa em si, mas apenas o seu sinal. "O signo linguístico une não uma coisa e uma palavra, mas um conceito e uma imagem acústica. Esta não é o som material, coisa puramente física, mas a impressão psíquica desse som, a representação que dele nos dá o testemunho de nossos sentidos." (SAUSSURE, 2006, p. 80).

O processo comunicativo é então um processo de sinais emitidos e compreendidos pelo interlocutor. Aquele que fala emite sinais, a possível compreensão desses sinais não depende daquele que fala, mas daquele que ouve.

\footnotetext{
${ }^{6}$ A arbitrariedade do signo é um aspecto a ser abordado na próxima seção.
} 
Nota-se até aqui, que o escopo fundamental da obra é a linguagem como veículo transmissor da ciência entre o mestre que fala e o discípulo que ouve. No entanto, a questão inicial continua enfática: essa transmissão é possível? Antes de respondê-la, é preciso expor a profunda análise que Agostinho realiza sobre a linguagem, em toda sua envergadura. (SOUZA, 2013, p. 126).

É importante frisar que o valor das palavras não reside nelas mesmas, mas naquilo que incitam, na sua capacidade evocativa. Seu valor é pragmático. "Até aqui chega o valor das palavras, das quais, porque quero atribuir-lhes muito, direi apenas que incitam a procurar as coisas, sem, porém, mostrá-las para que as conheçamos.” (AGOSTINHO, DM, XI, 36).

Diante de tais reflexões, é preciso compreender os signos em suas especificidades, os tipos de signos diferentes e a relação que estabelecem enquanto significantes com os tipos de coisas que são significadas, a relação entre signos recíprocos e não recíprocos. Descortinar os meandros inerentes ao universo dos signos encaminha a uma melhor compreensão de sua importância e necessidade dentro do processo comunicativo.

\section{A RELAÇÃO SIGNO E REALIDADE}

A linguagem é um sistema imperfeito. Ela se processa por meio de signos que são somente sinais daquilo que querem significar, assim sendo, não veiculam a verdade, mas sinalizam para ela com certa dificuldade. Os signos não são somente as palavras, embora sejam elas o objeto principal desta pesquisa: as palavras, que estão presentes na fala (som articulado) e escrita (forma gráfica). Nessa concepção, toda palavra é signo, mas nem todo signo é palavra.

\footnotetext{
À luz desses pressupostos, Agostinho analisa as palavras-sinal sob dois aspectos: o primeiro diz respeito aos sinais que significam outros sinais; o segundo diz respeito aos sinais que indicam coisas que não são sinais, ou seja, os objetos externos. Acrescenta-se a isso um terceiro aspecto distinto desses outros dois, a saber, as coisas que podem ser indicadas sem utilizar um sinal. (SOUZA, 2013, p. 126).
}

A relação do signo com sua realidade depende do tipo de signo utilizado no processo de comunicação. O Bispo de Hipona afirma que "quando falamos, fazemos sinais, donde provém a palavra significar (fazer sinais - signa facere)" (AGOSTINHO, DM, IV, 7). Quanto ao seu tipo, os signos podem ser: signos que veiculam apenas signos, signos que veiculam coisas e, na comunicação, pode-se ainda dizer de coisas que se veiculam sem signos. Cada tipo de signo corresponde a uma função específica dentro do processo de comunicação. 
Sendo assim, o primeiro aspecto se refere à função da sintática, ao passo que o segundo aspecto diz respeito às funções semânticas e pragmáticas. Já o terceiro pretende acentuar que o conhecimento não advém exclusivamente da linguagem, pois ele mesmo concede sentido à linguagem. (SOUZA, 2013, p. 126-127).

Os signos que veiculam apenas signos podem ser entendidos como sinais de sinais, nas palavras de Adeodato: “as letras escritas são sinais de sinais, quer dizer, sinais dos sons articulados pela voz" (AGOSTINHO, DM, IV, 8). Toda a discussão acerca dos sinais se vale de outros sinais como fundamentação. "É a real possibilidade de explicar as palavras por meio de outras palavras, ou seja, sinais que significam outros sinais.” (SOUZA, 2013, p. 127). Contudo, quando se discute sobre coisas, não são outras coisas que darão a fundamentação da mesma discussão, mas também sinais.

Os mais comuns são os signos que veiculam coisas. Essa relação de signo e “significáveis" é a preocupação agostiniana do capítulo VIII. O autor afirma que a discussão que se seguiu nos capítulos anteriores eram como que prelúdio para esta de maior relevo, ou seja, a relação signo e objeto. Para tanto, o Bispo de Hipona apresenta a emblemática questão: “Em primeiro lugar, dize-me se 'homem é homem?"” (AGOSTINHO, DM, VIII, 22). Agostinho questiona quanto à objetividade daquilo que é signo e daquilo que é seu referente real, a coisa.

O Capítulo III do $D M$ dedica-se à questão das coisas que podem ser mostradas sem o emprego de um sinal. Quanto a isto, é Adeodato quem conclui: "Na verdade, confesso que o som, o cheiro, o sabor, a gravidade, o calor e muitas outras coisas que pertencem aos outros sentidos, embora não se possam perceber sem os corpos, e por isto sejam corporais, não se podem todavia mostrar com o dedo." (AGOSTINHO, DM, III, 5). Certas ações podem ser ensinadas por meio de sua demonstração, a coisa em si, como o exemplo do caminhar (DM, III, $6)$.

No que se refere à reciprocidade dos sinais, tal relação pode ser percebida quando sinais sinalizam outros sinais. Como, por exemplo, signo e palavra, que possuem uma relação de reciprocidade, pois palavra pode ser utilizada como sinônimo de signo (KIRCHOF, 2011, p. 118). Toda palavra é signo, embora nem todo signo seja uma palavra. A não reciprocidade de signos também é evidenciada no exemplo anterior. Uma vez não recíprocos, eles não podem ser utilizados como equivalentes. Logo, existem signos recíprocos e não recíprocos. Segundo Kirchof (2011), os recíprocos podem possuir valores diferentes, valores iguais ou valores idênticos. Os pormenores dessa relação entre os signos dentro do conjunto da informação 
comunicada proporcionam o espaço semântico para o sentido. O salto signo para realidade depende da compreensão dessas intercambiações de valores.

Resta, para esta pesquisa, falar da arbitrariedade dos signos. O problema pode ser percebido em Agostinho no $D M(\mathrm{VI}, 8)$, quando ele apresenta a reciprocidade dos termos nomen e övoна. Ora, se ambos os termos, mesmo utilizando sinais gráficos diferentes dentro de suas línguas específicas, dizem respeito ao mesmo significado, pode-se concluir que um significado pode ter para isso mais de um signo, logo, os signos são arbitrários. Noutros termos,

\begin{abstract}
o laço que une o significante ao significado é arbitrário ou então, visto que entendemos por signo o total resultante da associação de uma significante com um significado, podemos dizer mais simplesmente: o signo linguístico é arbitrário. [...] Assim, a ideia de 'mar' não está ligada por relação alguma interior à sequência de sons $m-a-r$ que lhe serve de significante; poderia ser representada igualmente bem por outra sequência, não importa qual [...]. (SAUSSURE, 2006, p. 81-82, grifo do autor). ${ }^{7}$
\end{abstract}

Essa variação da possibilidade de utilização de signos para evocar uma mesma realidade (especialmente na utilização de idiomas diferentes) afirma a ideia que "as palavras não se relacionam diretamente com o valor e o conceito das coisas. Vê-se isso quando se observam outros idiomas" (XAVIER, 2014, p. 90). Como efeito dessa arbitrariedade, a vontade individual não é suficiente para determinar um signo, mas o conjunto linguístico como um todo. Os diferentes conjuntos linguísticos se valem de signos diferentes para dizer de uma mesma realidade. O sinal apenas indica a realidade externa; logo, não a substitui. A arbitrariedade dos signos não compromete a intenção final daquele que fala ou sinaliza.

\title{
CONCLUSÃO
}

Este trabalho teve por objetivo investigar como a linguagem, enquanto sons significativos, se expressa por meio de signos a partir do DM de Santo Agostinho. Esta relação acontece na utilização dos sinais como instrumentos a serviço da linguagem, para expressar na realidade o seu significado àquele que irá receber a mensagem. A linguagem nomeia a realidade por meio dos signos. Assim, como elementos significantes, os signos referem-se àquilo que está

\footnotetext{
7 A compreensão dos termos em Ferdinand de Saussure, em seu Curso de Linguística Geral, vale uma consideração a respeito dos termos do modo como ele os compreende: "O signo linguístico une não uma coisa e uma palavra, mas um conceito e uma imagem acústica. Esta não é o som material, coisa puramente física, mas a impressão psíquica desse som, a representação que dele nos dá o testemunho de nossos sentidos; tal imagem é sensorial e, se chegamos a chamá-la 'material', é somente neste sentido, e por oposição ao outro termo da associação, o conceito, geralmente mais abstrato." (SAUSSURE, 2006, p. 80).
} 
contido na memória e buscam significar na realidade para que haja a comunicação e compreensão dos elementos contidos da memória.

A linguagem é própria do ser humano, racional. Por meio dela, e de seus instrumentos diversos, ele se comunica, estabelece relações com outros de igual identidade. Os instrumentos da linguagem são sinais eficientes que levam ao êxito o processo relacional dos interlocutores da mesma linguagem. Esta brota da racionalidade humana, vale-se de instrumentos disponíveis, aponta significados, converte fonemas em sons significativos.

O processo relacional humano é um processo linguístico, racional, próprio dos seres humanos, insubstituível para a sua intersubjetividade ${ }^{8}$ e fundamental para que o processo comunicativo aconteça. Portanto, o homem pode ser considerado como um ser de linguagem. Pode-se afirmar que a linguagem é um tema filosófico, uma vez que ela gera questões, reflexões e conceitos referentes ao seu modo de operação, origem, instrumentos e finalidade.

A comunicação humana tem por objetivo uma dupla finalidade: ou ensinar (docere) ou recordar (commemorare). O primeiro tem como praticidade a ação de ensinar ou transmitir informações; o segundo busca efetivamente provocar a memória, seja de quem fala seja de quem ouve, a um processo de recordação dos conteúdos da mente. Quem ensina também aprende, pois falar é um ensinamento para ambos, especialmente quando se fala com o objetivo de despertar a memória em si mesmo. Portanto, ensinar e recordar chega a ser um só fato.

Pode-se concluir que não há comunicação sem sinais. A linguagem humana se dá por meio de sinais para se fazer compreendida. Sem a relação significante e significado por parte do sujeito, conclui-se que o processo comunicativo não chega a transmitir conteúdo inteligível.

Valendo-se de sinais, a linguagem encontra, contudo, os obstáculos que eles apresentam, uma vez que são instrumentos imperfeitos, sinais intermediários. Logo, o êxito e a eficiência do uso dos signos no processo de comunicação carecem não apenas da emissão de signos, mas da sua reta articulação, escuta do que se diz e entendimento da mensagem enunciada.

\section{REFERÊNCIAS}

AGOSTINHO, Santo. De magistro. Tradução de Angelo Ricci. 3. ed. São Paulo: Abril Cultural, 1984. (Os Pensadores).

\footnotetext{
${ }^{8} \mathrm{O}$ termo aqui utilizado conota certo grau de anacronismo, uma vez que é utilizado fora da discussão moderna dele. Não se trata de uma subjetividade cartesiana, um conceito muito recente, mas uma relação comum de interioridade.
} 
AGOSTINHO, Santo. Confissões. Tradução J. Oliveira Santos e A. Ambrósio de Pina. 3. ed. São Paulo: Abril Cultural, 1984. (Os Pensadores).

GILSON, Étienne. Introdução ao estudo de Santo Agostinho. Tradução Cristiane Negreiros Abbud Ayoub. São Paulo: Discurso Editorial; Paulus, 2006.

KIRCHOF, Edgar Roberto. Teoria dos signos na idade média: A semiótica de Santo Agostinho. Acta Semiótica et Lingvistica, v. 16, n. 2, p. 113-160, jul./dez. 2011. Disponível em: http://www.periodicos.ufpb.br/index.php/actas/issue/view/1164/showToc. Acesso em: 06 nov. 2018.

MAIA, Renan P.; JÚNIOR, Carlos B. L. Os limites da linguagem na aquisição do conhecimento segundo Santo Agostinho. Revista TCBrasil, João Pessoa, v. 1, n. 1, p. 70-86, jul. 2017. Disponível em: http://revistatcbrasil.com.br/wp-content/uploads/2017/08/111.pdf. Acesso em: 05 nov. 2018.

PESSANHA, José Américo Motta. Santo Agostinho. Vida e Obra. In: AGOSTINHO. Confissões. De Magistro. Tradução J. Oliveira Santos e A. Ambrósio de Pina. 3. ed. São Paulo: Abril Cultural, 1984. p. VII-XX. (Os Pensadores).

SANTOS, Bento Silva. O De Magistro de Agostinho e o problema da Linguagem. In: COSTA, José Raimundo da. (ed.). Ensaios e estudos. Belo Horizonte: O Lutador, 1997. p. 151-169.

SANTOS, João Tiago Costa. Da linguagem agostiniana: Em busca do Mestre Interior. Covilhã: Universidade da Beira Interior, 2010. Disponível em: http://www.lusosofia.net/textos/santos_joao_tiago_costa_linguagem.pdf. Acesso em: $21 \mathrm{dez}$. 2019. (Artigos LUSOSOFIA).

SAUSSURE, Ferdinand de. Curso de Linguística Geral. Organização de Charles Bally e Albert Sechehaye. Tradução Antônio Chelini, José Paulo Paes e Izidoro Blikstein. 27. ed. São Paulo: Cultrix, 2006.

SOUZA, Edy Klévia Fraga de. As funções da linguagem na obra De Magistro de Santo Agostinho. In: CARVALHO, Marcelo; FIGUEIREDO, Vinícius (org.). Filosofia Antiga e Medieval. São Paulo: ANPOF, 2013. p. 125-132. Disponível em: https://www.ricardocosta.com/sites/default/files/pdfs/anpof_xv1__filosofia_antiga_e_medieval.pdf. Acesso em: 13 maio 2020.

XAVIER, Glaúcia do Carmo. Significante e significado no processo de alfabetização e letramento: contribuições de Saussure. Cadernos CESPUC de pesquisa, Belo Horizonte, v. 1, n. 25, p. 87-102, 2014. Disponível em:

http://periodicos.pucminas.br/index.php/cadernoscespuc/issue/view/744. Acesso em: 05 nov. 2018. 